\title{
The Potential Role of Radionuclide Imaging in Osteoporotic Vertebral Fracture and Sacral Fracture
}

\section{Abstract}

Vertebral fractures (VF) and sacral insufficiency fractures (SIFs) are very common in osteoporotic patients with low-back pain and are often overlooked in clinical practice. Plain radiography is usually the first examination. However, on many occasions, further evaluation with CT scan, MRI and nuclear medicine studies is necessary. Nuclear medicine examinations have important applications for the detection and timing of fractures and prediction of response to therapy. Bone scan is a simple study for the evaluation of osteoporotic patients with low-back pain to detect VF or SIFs, to identify an alternative diagnosis, to assess the age of fracture, and to predict the response to vertebroplasty. Bone scan is also helpful to detect other foci of insufficiency fractures, or other co-existent disease in the rest of the total body. Other radionuclide studies such as ${ }^{67} \mathrm{Ga}$, ${ }^{99} \mathrm{mTC}-\mathrm{MIBI}$, and ${ }^{18} \mathrm{~F}$-FDG PET$\mathrm{CT}$ are also useful to diagnose co-existent diseases or other alternative conditions such as osteomyelitis or primary and metastatic bone diseases. The purpose of this article is to review the potential role of nuclear medicine studies in osteoporotic vertebral fractures and sacral fractures.

Keywords: Osteoporosis; Vertebral fracture; Radionuclide study; Bone scan; Sacral insufficiency fracture.

Abbreviations: VF: Vertebral Fractures; SIFs: Sacral Insufficiency Fractures; BMD: Bone Mineral Density; CT: Computerized Tomography; MRI: Magnetic Resonance Imaging; SPECT: Single Photon Emission Tomography; MDP: 99mTc - Methylene

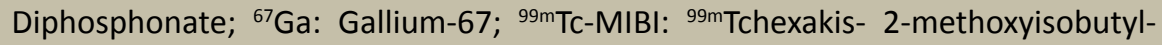
isonitrile; ${ }^{18} \mathrm{~F}-\mathrm{FDG}:{ }^{18} \mathrm{~F}$-fluorodeoxyglucose; SUV: Standardised Uptake Value; PET: Positron Emission Tomography

Received: December 01, 2015; Accepted: January 05, 2016; Published: January 08, 2016

\section{Introduction}

A vertebral fracture (VF) is the most common fracture in osteoporosis with a prevalence of as high as $12 \%$ in women and $12-14 \%$ in men which increases by age [1-3] "One vertebral fracture" is the most common form of VF, but in up to $30 \%$ of cases there are "two or more vertebral fractures" [2]. Vertebral fracture has a great influence on prognosis, quality of life, morbidity and mortality of osteoporotic patients [4-7]. It is a powerful predictor of future vertebral and nonvertebral fractures, independent of the bone mineral density (BMD) values [8]. Studies have suggested that patients with low BMD and a VF can benefit from appropriate treatment $[9,10]$. However, on many occasions, VFs are under-

\section{Reza Vali", Lydia Bajno, Mahnaz Kousha² and Charron Martin ${ }^{3}$}

1 Department of Diagnostic Imaging, Division of Nuclear Medicine, University of Toronto, Toronto, Ontario, Canada

2 Nuclear Medicine Physician, Research Student in University of Toronto, Toronto, Ontario, Canada

3 Department of Nuclear Medicine, Brampton Nuclear Services, Brampton, Ontario, Canada

Corresponding author: Reza Vali

¡reza.vali@sickkids.ca

Assistant Professor of Nuclear Medicine. Department of Diagnostic Imaging, Division of Nuclear Medicine, The Hospital for Sick Children, University of Toronto, Toronto, Ontario, Canada.

\section{Tel: 4168757918}

Citation: Vali R, Bajno L, Kousha M, et al.The Potential Role of Radionuclide Imaging in Osteoporotic Vertebral Fracture and Sacral Fracture. Spine Res. 2015, 2:1. 
were calculated based on the adjudicated discrepancies between the local and central reading, with the later as the "reference standard' [15]. Sacral insufficiency fractures (SIFs) are also a common cause of debilitating low-back pain in elderly patients with osteoporosis which are often overlooked $[16,17]$. The actual incidence of SIFs is not well studied but has been reported to be between $1 \%$ and $5 \%$ in at-risk patient populations $[18,19]$. Plain radiography is usually the first investigation for the detection of VFs 4 and SIFs. However, on many occasions, further evaluation with computerized tomography (CT) scan, magnetic resonance imaging (MRI) or radionuclide studies is necessary. MRI has a high sensitivity for detection of vertebral or sacral fractures and should be used if there is a concern about underlying pathology (e.g. tumor, infection) [20,21]. However, it is not easily available at some institutions, the length of study is not feasible for some patients, and in some cases there are contraindications to perform MRI such as the presence of metal rods, CT scan is less sensitive for sacral fractures but can be used for inconclusive or equivocal results on nuclear medicine studies or MRI. Unlike nuclear medicine studies or MRI, CT scan is not useful in determining the age of fracture. In this article, the potential role of radionuclide scans in osteoporotic VFs and SIFs is reviewed.

\section{Bone scan}

Bone scan has been accepted as an important modality for the detection and evaluation of malignant and benign bone pathologies for over 50 years [22]. The main advantage of bone scan is its high sensitivity in detecting bone abnormality, often before any structural manifestation. In addition, the ability to evaluate the total body in one study, as well as its availability and low cost, makes it a useful modality to locate, diagnose, and evaluate bone pathology [23]. With the new Single Photon Emission Tomography (SPECT) technique, the ability of bone scan to detect small bone lesions and localize them has also improved $[24,25]$. Tc - methylene diphosphonate (MDP) is the most commonly used radiotracer which accumulates in sites of increased bone turnover. The mechanism of radiotracer accumulation depends on the vascularity and increased osteoblastic activity of bone [26]. Osteoporosis is defined as a systemic skeletal disorder, characterized by compromised bone strength, low bone 5 mass and micro-architectural deterioration of bone tissue, predisposing to increased bone fragility, and risk of fractures [27]. Although there are different scintigraphic patterns that may be visualized in osteoporosis, such as relatively low skeletal uptake of tracer and poor vertebral delineation (decreased bone to background ratios), the role of bone scan in the diagnosis of uncomplicated osteoporosis is limited [28]. Bone scan is especially helpful for evaluating suspected fractures where radiography is not diagnostic, either because of poor sensitivity related to the anatomical site of the fracture (e.g.sacrum), because adequate views are not obtainable with radiography due to the patient's condition, or in cases of fracture with no or minimal loss of vertebral height (occult VF) [29]. Sometimes the minimum threshold of vertebral height loss for detection by radiography occurs in days or weeks after the initiation of actual fracture (i.e. a fractured vertebrae is still fracturing) [8]. Thus, during this lag phase in a patient with osteoporosis and recent onset back pain, bone scan can be helpful to detect the VF. Bone scan is a good modality to assess the age of fracture (i.e. to detect a recent VF). A compression fracture of the vertebrae is simply identified as the loss of vertebral height with intense horizontal linear activity. This activity then fades over a period of 6 to 24 months, which therefore allows the intensity of uptake to help evaluate the timing of fracture. Thus, bone scan is particularly useful to differentiate an acute or sub-acute fracture from an old fracture $[30,31]$. In a study by Matin, $90 \%$ and $97 \%$ of the cases of VF found on a bone scan normalized within two and three years, respectively [30]. This is important in an osteoporotic patient with history of VFs and recent back pain, or in a patient with recent trauma to diagnose the cause of back pain, as well as from the medicolegal point of view, especially when there is a contraindication to obtain an MRI $[32,33]$. Since vertebral deformities are frequently seen in older women, the presence of radiographic vertebral deformity doesn't necessarily mean that a VF or a vertebral abnormality is the cause $[5,34]$. A normal bone scan in a patient with back pain and previous vertebral fractures identified on radiographs can exclude recent VF as the cause of symptoms. This is helpful in elucidating the etiology of back pain and can impact patient management. In many cases, bone scan is a complementary modality to radiography to detect the VF and coexistent disease or to exclude a recent VF. Cook et al. evaluated the role of bone scan in 60 osteoporotic patients with back pain [35]. In 14 patients, a VF was considered to be the only cause of pain, while in 38 patients other alternative abnormalities were found. Six patients with radiographic evidence of a vertebral deformity had normal bone scans and were considered to have old healed fractures or other vertebral deformities that were not due to recent fracture. Bone scan changed the management in 18 patients and excluded VF as a cause of symptoms in 30. SPECT bone scan is also useful to predict the response to vertebroplasty in an osteoporotic VF. Percutaneous vertebroplasty (PVP) is a minimally invasive radiological procedure intended for relieving painful vertebral fractures, and it is most useful for acute osteoporotic fractures [36,37]. Targeting the vertebroplasty is especially important in cases of multiple vertebral fractures if they are variable in age, and in patients with non-localizing pain. In a study by Sola et al., the value of bone SPECT-CT was evaluated on 33 consecutive patients with chronic pain due to a VF planned for PVP [38]. Twenty four patients finally underwent PVP. Positive SPECT-CT images (i.e. increased activity on bone scan at the site of abnormality on CT) predicted clinical improvement in 91\% (21 of 23) of the patients. A subgroup of 25 patients had both SPECT$\mathrm{CT}$ and MRI within one month. The agreement between SPECT-CT and MRI in detection of acute VF was $80 \%$ (20 of 25). Bone scan showed other causes of back pain in certain cases, such as a new fracture or multiple co-existing fractures, facet and discal degenerative changes, and persisting bone remodelling in a previously cemented vertebrae. A positive bone SPECT-CT seemed to be a good predictor of post vertebroplasty response and it was especially useful in patients who could not undergo MRI ( 8 patients). In a study by Masala et al. both MRI and scintigraphy were accurate in the assessment of fractures less than four months old, but scintigraphy was more accurate after four months [39]. In another study by Dafydd et al. the value of combined use of MRI, and bone scan for prediction of response to PVP was studied [40]. In this retrospective study, 39 patients 
with a total of 73 VF were treated with PVP. The agreement between MRI and bone scan was $63 \%$. However, based on bone scan, almost twice as many fractures were classified as 'acute/ subacute' than on MRI. They concluded that by using MRI without a bone scan, $48.2 \%$ of the potentially suitable vertebroplasty targets ( $37 \%$ of the total vertebral lesions) would likely have been overlooked. Bone scan and MRI clearly provide different but complementary information on VFs, and combining the modalities is useful for vertebroplasty selection and planning in osteoporotic VFs. Kim et al. found similar findings, with a $55 \%$ concordance between MRI and bone scan in 44 patients ( 87 vertebrae). In their study, the agreement between MRI and bone scan for detection of new findings in only one vertebra was $96 \%$, in two levels was $50 \%$, and in three or more levels was $36 \%$. However, they concluded that when more than one area of increased activity is detected, bone scan may be overestimating the number of acute fractures, and multiple hot spots should be interpreted cautiously [41]. Vertebral fractures may also be seen in other conditions such as osteomalacia, osteoporosis secondary to glucocorticoid intake, hyperparathyroidism, chronic kidney disease, and after trauma [42]. Thus, further evaluation with MRI or bone scan is useful if underlying pathology or co-existing disease is suspected. It is not uncommon to detect other insufficiency fractures in the rest of the total body, which can influence the management. It is also not infrequent to detect coexisting diseases, such as avascular necrosis, metastases, Paget diseases, multiple myeloma, and metabolic bone disease on a bone scan. The spine is the third most common site for metastatic disease, following the lung and liver. Approximately $60-70 \%$ of patients with systemic cancer will have spinal metastasis [43]. Bone scan and MRI are helpful to differentiate osteoporotic versus metastatic vertebral fractures [44]. The finding of multiple asymmetric foci of increased uptake in the axial and appendicular skeleton is characteristic of osseous metastases, especially with a known primary tumor [43].

\section{Gallium scan}

Gallium-67 $\left({ }^{67} \mathrm{Ga}\right)$ scintigraphy has a unique application in detection, staging, and response to therapy of specific tumors (e.g. Iymphoma), and also in the diagnosis and response to therapy of infectious process such as osteomyelitis. It is specifically useful to diagnose osteomyelitis in violated bone (i.e. fracture, after surgery, with a prosthesis). The mechanism of ${ }^{67} \mathrm{Ga}$ uptake is complex and includes direct leukocyte and bacterial uptake, binding to lactoferrin and transferrin, and accumulation in the areas of increased vascularity and increased bone turnover $[45,46]$. The presence of vertebral uptake in VFs makes it difficult to diagnose osteomyelitis on a bone scan in patients with osteoporotic VFs. This is particularly important since a delay in the treatment of vertebral osteomyelitis may lead to irreversible complications. In patients with osteoporosis and a VF, osteomyelitis should be considered when there is severe back pain, persistent unexplained fever, unexplained elevation of the erythrocyte sedimentation rate, or bacteremia without an obvious extra-vertebral focus of infection, particularly if the patient is immunocompromised [47]. If vertebral osteomyelitis is in differential diagnosis, further evaluation with ${ }^{67} \mathrm{Ga}$ scintigraphy may address the problem. A Gallium scan is suggestive of osteomyelitis if the uptake on ${ }^{67} \mathrm{Ga}$ scan exceeds that of the bone scan and/or if ${ }^{67} \mathrm{Ga}$ uptake differs in distribution (incongruent or more extensive), compared with that on bone scan. A congruent distribution pattern (i.e. similar size and intensity) of ${ }^{67} \mathrm{Ga}$ and bone scan, especially if the intensity of activity is lower on ${ }^{67} \mathrm{Ga}$ scan, is suggestive of healing bone. However, this finding may also be seen in chronic low-grade osteomyelitis. A combined bone scan and ${ }^{67} \mathrm{Ga}$ scintigraphy has a good sensitivity and specificity for the diagnosis of vertebral osteomyelitis. In case of a normal gallium scan, the diagnosis of acute osteomyelitis is very unlikely with a high degree of certainty (negative predictive value 90$100 \%$ ) [45]. ${ }^{67} \mathrm{Ga}$ scintigraphy may also show adjacent or distant soft tissue infection which can be helpful to detect the source of infection in an osteoporotic patient with a VF and fever [48]. Following successful treatment of vertebral osteomyelitis, uptake of Gallium usually decreases. Bone scan may remain abnormal for a longer period of time. Therefore, bone scan is not a good modality to assess the short term response to the therapy. If the Gallium scan does return to normal, a cure can be predicted with high reliability.

\section{9mTC-MIBI}

${ }^{99 m}$ Tc-hexakis-2-methoxyisobutyl-isonitrile ( $\left.{ }^{99 \mathrm{~m}} \mathrm{Tc}-\mathrm{MIBI}\right)$ has been used for myocardial perfusion study for decades. ${ }^{99 m} \mathrm{Tc}-\mathrm{MIBI}$ can also concentrate on tumor cells likely due to higher concentration of intracellular mitochondria. Thus, it can potentially play a complementary role to ${ }^{99 \mathrm{~m} T c-M D P}$ bone scan in cases of high suspicion for vertebral metastases to differentiate between a VF with and without osteomyelitis versus tumoral involvement. In a study by Buyukdereli et al. done to compare ${ }^{99 \mathrm{~m}} \mathrm{TC}-\mathrm{MIBI}$ scintigraphy with bone scan to determine whether $99 \mathrm{mTc}-\mathrm{MIBI}$ could distinguish vertebral metastases from VF, 20 patients with a non-malignant VF and 14 patients with a metastasis to the vertebrae were included [49]. On conventional bone scans, radiotracer activity was increased in $92 \%$ of VFs and in $100 \%$ of vertebral metastases. However, on MIBI scan no abnormality was observed in VF, but in $73 \%$ of vertebral metastases the MIBI activity was increased. ${ }^{18} \mathrm{~F}-\mathrm{FDG}$ PET-CT PET-CT has been successfully used in the diagnosis, staging, response to therapy, and evaluation of recurrence in various malignant tumors with high diagnostic accuracy. Increased consumption of glucose is a characteristic of most cancers, and in part, relates to overexpression of the GLUT-1 glucose transporters and increased hexokinase activity. ${ }^{18} \mathrm{~F}$-fluorodeoxyglucose $\left({ }^{18} \mathrm{FFDG}\right)$ is the analogue of glucose which accumulates in tissue proportional to the amount of glucose utilisation. While the majority of tumors typically present as marked increased FDG activity, traumatic fractures may be negative or demonstrate only mild increased activity. ${ }^{18}$ FDG may also accumulate in the areas of inflammation or infection. Therefore, ${ }^{18} \mathrm{~F}-\mathrm{FDG}$ PET may allow differentiation between an osteoporotic compression fracture and compression fractures with underlying tumoral involvement (either primary or metastatic), or compression fractures with superimposed infection (vertebral osteomyelitis), particularly when MRI is either equivocal or contraindicated [50-53]. In a prospective study for the evaluation of ${ }^{18} \mathrm{~F}$-FDG PET-CT in comparison to bone scan and 67Ga scintigraphy for the diagnosis of spondylodiskitis in 34 patients, Fuster et al. showed a better result for ${ }^{18} \mathrm{~F}$-FDG PETCT [54]. The sensitivity and specificity of combined bone scan and 
${ }^{67} \mathrm{Ga}$ were $78 \%$ and $81 \%$, respectively, with a positive predictive value of $82 \%$, a negative predictive value of $76 \%$, and an overall accuracy of $79 \%$. The sensitivity and specificity of PETCT were $89 \%$ and $88 \%$, respectively, with a positive predictive value of $89 \%$, a negative predictive value of $87 \%$, and an overall accuracy of $88 \%$. In another study, the sensitivity of ${ }^{18} \mathrm{FFDG} \mathrm{PET}$ alone and ${ }^{18} \mathrm{~F}$-FDG PET-CT for detection of spinal metastases was $74 \%$ and $98 \%$, respectively [55]. The intensity of FDG activity is also helpful to diagnose malignancy. Cho et al. found a cut-off of 4.25 for Standardised Uptake Value (SUV) to differentiate malignant VF versus VFs without malignancy with a sensitivity of $85 \%$ and specificity of $71 \%$ [56]. In this study, the sensitivity and specificity of MRI for diagnosis of malignancy was $64 \%$ and $83 \%$, respectively. In another study by Shin et al. to differentiate malignant VFs from benign VFs in 34 patients with VFs (19 malignant and 15 benign fractures), the sensitivity, specificity and diagnostic accuracy of F-18 FDG PET-CT were $89.5 \%, 86.7 \%$ and $88.2 \%$, respectively, with a cut-off SUVmax set at 4.7 [57]. The time interval between fracture and $\mathrm{PET} / \mathrm{CT}$ did not significantly influence FDG uptake at the fracture site. In malignancy, ${ }^{18}$ F-FDG PET-CT may also show other sites of tumoral involvement or metastases both in the bone/bone marrow and/or in the soft tissues.

\section{Sacral insufficiency fracture}

Sacral insufficiency fractures (SIFs) are a common but usually under-diagnosed cause of low back pain, especially in older patients with osteoporosis [16,17]. Other factors which may increase the risk of SIFs are rheumatoid arthritis, Paget disease, hyperparathyroidism, corticosteroid use, renal disease and pelvic radiation [18,58-61]. The sacrum is the part of the pelvis which transmits the weight of the body to the pelvic girdle. The SIFs occur when the sacrum cannot bear the stress of body weight. Thus, the SIFs usually occur parallel to the vertebrae (mostly in the ala). The patient usually suffers from a vague severe pain in the buttock and low back radiating to hip, groin and pelvis [58]. Plain radiographs are often negative but may show non-specific sclerosis in half of the patients, and a fracture line in $10-20 \%$ of the cases $[18,59]$. The same findings may be seen with CT scan. CT scan is one of the best modalities to detect the fracture line. However, CT scan has $15-25 \%$ false-negative results $[59,62]$.
Although CT scan is not as sensitive as MRI or bone scan for the detection of SIFs, it may be indicated in cases of equivocal findings on MRI or bone scan, or for better delineation of fracture lines, if sacroplasty is a potential treatment plan for the patient $[63,64]$. CT scan is also helpful to differentiate SIFs and metastases, which is important in older patients, especially with a history of a primary malignancy [62]. The presence of gas in the ventral part of fracture, the so-called "vacuum phenomenon", is suggestive of fractures and is not seen in metastases [65]. MRI and bone scan have the highest sensitivity for the detection of SIFs. MRI is very sensitive in detecting marrow edema, which presents as an area of increased signal intensity on T2-weighted and inversion-recovery images and low-signal intensity on T1-weighted images, as well as fracture lines within the area of edema $[66,67]$. However, the areas of low-signal intensity on T1 may mimic metastatic disease leading to unnecessary biopsies $[59,68]$. MRI is also useful to exclude an adjacent soft tissue mass. Bone scan is probably the most sensitive modality to detect SIFs $[59,69]$. Since SIFs usually occur parallel to the spine in the sacral ala, bone scan shows increased uptake bilaterally adjacent to the sacral ala. The uptake may also be seen horizontally between the ala which makes a socalled " $\mathrm{H}$ " or "butterfly" appearance (Honda sign) across the sacrum. The " $H$ " pattern or "Honda" sign is typical for SIFs, and is diagnostic in an appropriate clinical setting [69]. However, this pattern is seen only in about $40 \%$ of the cases $[67,70]$. Other patterns of SIFs are unilateral uptake in the sacral ala with or without a horizontal uptake, or multiple small foci of uptake in the ala or sacrum [71]. The sensitivity of bone scan to detect SIFs is greater than 95\% especially when adding SPECT technique [71]. Bone scan is also useful to evaluate other sites of skeletal system for the detection of silent foci of insufficiency fractures.

\section{Conclusions}

Vertebral fractures and sacral insufficiency fractures are common causes of low back pain in osteoporotic patients, which are usually underdiagnosed with routine plain radiography. Nuclear medicine examinations including bone scan have complementary roles for the detection and timing of fractures, prediction of response to therapy, diagnosis of co-existent diseases and evaluation of the total body. Further prospective studies are needed to establish 
the exact clinical indication of bone SPECT versus MRI in different clinical scenarios.

\section{References}

1 O'Neill TW, Felsenberg D, Varlow J, Cooper C, Kanis JA, et al. (1996) The prevalence of vertebral deformity in european men and women: the European Vertebral Osteoporosis Study. J Bone Miner Res 11: 10101018.

2 Waterloo S (2012) Prevalence of vertebral fractures in women and men in the population-based Tromso Study. BMC Musculoskelet Disord 13: 3.

3 Samelson EJ, Hannan MT, Zhang Y, Genant HK, Felson DT, et al. (2006) Incidence and risk factors for vertebral fracture in women and men: 25 year follow-up results from the population-based Framingham study. J Bone Miner Res 21: 1207-1214.

4 Lips P, van Schoor NM (2005) Quality of life in patients with osteoporosis. Osteoporos Int 16: 447-455.

5 Crans GG, Silverman SL, Genant HK, Glass EV, Krege JH (2004) Association of severe vertebral fractures with reduced quality of life: reduction in the incidence of severe vertebral fractures by teriparatide. Arthritis Rheum 50: 4028-4034.

6 Bliuc D, Nguyen ND, Milch VE, Nguyen TV, Eisman JA, et al. (2009) Mortality risk associated with low-trauma osteoporotic fracture and subsequent fracture in men and women. JAMA 301: 513-521.

7 O'Neill TW, Cockerill W, Matthis C, Raspe HH, Lunt M, et al. (2004) Back pain, disability, and radiographic vertebral fracture in European women: a prospective study. Osteoporos Int 15: 760-765.

8 McKiernan FE (2009) The broadening spectrum of osteoporotic vertebral fracture. Skeletal Radiol 38: 303-308.

9 Sambrook P, Cooper C (2006) Osteoporosis. Lancet 367: 2010-2018.

10 Schwartz AV, Bauer DC, Cummings SR, Cauley JA, Ensrud KE, et al. (2010) Efficacy of continued alendronate for fractures in women with and without prevalent vertebral fracture: the FLEX trial. J Bone Miner Res 25: 976-982.

11 Williams AL, Al-Busaidi A, Sparrow PJ, Adams JE, Whitehouse RW (2009) Under-reporting of osteoporotic vertebral fractures on computed tomography. Eur J Radiol 69: 179-183.

12 Fechtenbaum J, Cropet C, Kolta S, Verdoncq B, Orcel P, et al. (2005) Reporting of vertebral fractures on spine X-rays. Osteoporos Int 16 : 1823-1826.

13 Fink HA, Milavetz DL, Palermo L, Nevitt MC, Cauley JA, et al. (2005) What proportion of incident radiographic vertebral deformities is clinically diagnosed and vice versa? J Bone Miner Res 20: 1216-1222.

14 Gehlbach SH, Bigelow C, Heimisdottir M, May S, Walker M, et al. (2000) Recognition of vertebral fracture in a clinical setting. Osteoporos Int 11: 577-582.

15 Delmas PD, van de Langerijt L, Watts NB, Eastell R, Genant H, et al. (2005) Underdiagnosis of vertebral fractures is a worldwide problem: the IMPACT study. J Bone Miner Res 20: 557-563.

16 Lee YJ, Bong HJ, Kim JT, Chung DS (2008) Sacral insufficiency fracture, usually overlooked cause of lumbosacral pain. J Korean Neurosurg Soc 44: 166-169.

17 Wild A, Jaeger M, Haak H, Mehdian SH (2002) Sacral insufficiency fracture, an unsuspected cause of low-back pain in elderly women. Arch Orthop Trauma Surg 122: 58-60.
18 Lyders EM, Whitlow CT, Baker MD, Morris PP (2010) Imaging and treatment of sacral insufficiency fractures. AJNR Am J Neuroradiol 31: 201-210.

19 Weber M, Hasler P, Gerber H (1993) Insufficiency fractures of the sacrum. Twenty cases and review of the literature. Spine (Phila Pa 1976) 18: 2507-2512.

20 Jarvik JG, Deyo RA (2002) Diagnostic evaluation of low back pain with emphasis on imaging. Ann Intern Med 137: 586-597.

21 Tins BJ, Cassar-Pullicino VN, Lalam RK (2007) Magnetic resonance imaging of spinal infection. Top Magn Reson Imaging 18: 213-222.

22 Scharf S (2009) SPECT/CT imaging in general orthopedic practice. Semin Nucl Med 39: 293-307.

23 Mariani G, Bruselli L, Kuwert T, Kim EE, Flotats A, et al. (2010) A review on the clinical uses of SPECT/CT. Eur J Nucl Med Mol Imaging 37: 1959-1985.

24 Strobel K, Burger C, Seifert B, Husarik DB, Soyka JD, et al. (2007) Characterization of focal bone lesions in the axial skeleton: performance of planar bone scintigraphy compared with SPECT and SPECT fused with CT. AJR Am J Roentgenol 188: W467-474.

25 Even-Sapir E, Metser U, Mishani E, Lievshitz G, Lerman H, et al. (2006) The detection of bone metastases in patients with high-risk prostate cancer: 99mTc-MDP Planar bone scintigraphy, single- and multi-field-of-view SPECT, 18F-fluoride PET, and 18F-fluoride PET/CT. J Nucl Med 47: 287-297.

26 Fogelman I (1980) Skeletal uptake of diphosphonate: a review. Eur J Nucl Med 5: 473-476.

27 Bernabei R, Martone AM, Ortolani E, Landi F, Marzetti E (2014) Screening, diagnosis and treatment of osteoporosis: a brief review. Clin Cases Miner Bone Metab 11: 201-207.

28 Moore AE, Blake GM, Taylor KA, Ruff VA, Rana AE, et al. (2012) Changes observed in radionuclide bone scans during and after teriparatide treatment for osteoporosis. Eur J Nucl Med Mol Imaging 39: 326-336.

29 Pham T, Azulay-Parrado J, Champsaur P, Chagnaud C, Legré V, et al. (2005) "Occult" osteoporotic vertebral fractures: vertebral body fractures without radiologic collapse. Spine (Phila Pa 1976) 30: 2430-2435.

30 Matin P (1979) The appearance of bone scans following fractures, including immediate and long-term studies. J Nucl Med 20: 1227-1231.

31 Spitz J, Lauer I, Tittel K, Wiegand H (1993) Scintimetric evaluation of remodeling after bone fractures in man. J Nucl Med 34: 1403-1409.

32 Versijpt J, Dierckx RA, De Bondt P, Dierckx I, Lambrecht L, et al. (1999) The contribution of bone scintigraphy in occupational health or medical insurance claims: a retrospective study. Eur J Nucl Med 26: 804-811.

33 Tang ZB, Lei Z, Yang HL, Chen KW (2012) Value of bone scan imaging in determining painful vertebrae of osteoporotic vertebral compression fractures patients with contraindications to MRI. Orthop Surg 4: 172176.

34 Roux C, Priol G, Fechtenbaum J, Cortet B, Liu-Léage S, et al. (2007) A clinical tool to determine the necessity of spine radiography in postmenopausal women with osteoporosis presenting with back pain. Ann Rheum Dis 66: 81-85.

35 Cook GJ, Hannaford E, See M, Clarke SE, Fogelman I (2002) The value of bone scintigraphy in the evaluation of osteoporotic patients with back pain. Scand J Rheumatol 31: 245-248. 
36 Barr JD, Barr MS, Lemley TJ, McCann RM (2000) Percutaneous vertebroplasty for pain relief and spinal stabilization. Spine (Phila Pa 1976) 25: 923-928.

37 Jensen ME (1997) Percutaneous polymethylmethacrylate vertebroplasty in the treatment of osteoporotic vertebral body compression fractures: technical aspects. AJNR Am J Neuroradiol 18: 1897-1904.

38 Solá M, Pérez R, Cuadras P, Díaz R, Holgado S, et al. (2011) Value of bone SPECT-CT to predict chronic pain relief after percutaneous vertebroplasty in vertebral fractures. Spine J 11: 1102-1107.

39 Masala S, Schillaci O, Massari F, Danieli R, Ursone A, et al. (2005) $\mathrm{MRI}$ and bone scan imaging in the preoperative evaluation of painfu vertebral fractures treated with vertebroplasty and kyphoplasty. In Vivo 19: 1055-1060.

40 ap Dafydd D, Salem S, Zerizer I, Yan Mok W, Gishen P, et al. (2014) The value of combined assessment of vertebral fractures with $99 \mathrm{mTc}$ MDP scintigraphy and MRI in selecting and planning percutaneous vertebroplasty. Nucl Med Commun 35: 755-761.

41 Kim JH, Kim JI, Jang BH, Seo JG, Kim JH (2010) The comparison of bone scan and $\mathrm{MRI}$ in osteoporotic compression fractures. Asian Spine J 4: 89-95.

42 Panda A, Das CJ, Baruah U (2014) Imaging of vertebral fractures. Indian J Endocrinol Metab 18: 295-303.

43 Shah LM, Salzman KL (2011) Imaging of spinal metastatic disease. Int J Surg Oncol: 769753.

44 Griffith JF, Guglielmi G (2010) Vertebral fracture. Radiol Clin North Am 48: 519-529.

45 Palestro CJ (1994) The current role of gallium imaging in infection. Semin Nucl Med 24: 128-141.

46 Stokkel MP, Takes RP, van Eck-Smit BL, Baatenburg de Jong RJ (1997) The value of quantitative gallium-67 single-photon emission tomography in the clinical management of malignant external otitis. Eur J Nucl Med 24: 1429-1432.

47 McHenry MC, Duchesneau PM, Keys TF, Rehm SJ, Boumphrey FR (1988) Vertebral osteomyelitis presenting as spinal compression fracture. Six patients with underlying osteoporosis. Arch Intern Med 148: 417-423.

48 Love C, Patel M, Lonner BS, Tomas MB, Palestro CJ (2000) Diagnosing spinal osteomyelitis: a comparison of bone and Ga-67 scintigraphy and magnetic resonance imaging. Clin Nucl Med 25: 963-977.

49 Buyukdereli G, Ermin T, Kara O, Kibar M (2006) Tc-99m MIBI uptake in traumatic vertebral fractures and metastatic vertebral lesions: comparison with Tc-99m MDP. Adv Ther 23: 33-38.

50 Bredella MA, Essary B, Torriani M, Ouellette HA, Palmer WE (2008) Use of FDG-PET in differentiating benign from malignant compression fractures. Skeletal Radiol 37: 405-413.

51 Elgazzar AH, Kazem N (2009) Metastatic bone disease: evaluation by functional imaging in correlation with morphologic modalities. Gulf J Oncolog : 9-21.

52 Kato K, Aoki J, Endo K (2003) Utility of FDG-PET in differential diagnosis of benign and malignant fractures in acute to subacute phase. Ann Nucl Med 17: 41-46

53 Schmitz A, Risse JH, Textor J, Zander D, Biersack HJ, et al. (2002) FDG-PET findings of vertebral compression fractures in osteoporosis: preliminary results. Osteoporos Int 13: 755-761.
54 Fuster D, Solà O, Soriano A, Monegal A, Setoain X, et al. (2012) A prospective study comparing whole-body FDG PET/CT to combined planar bone scan with 67Ga SPECT/CT in the Diagnosis of Spondylodiskitis. Clin Nucl Med 37: 827-832.

55 Metser U, Lerman H, Blank A, Lievshitz G, Bokstein F, et al. (2004) Malignant involvement of the spine: assessment by $18 \mathrm{~F}-\mathrm{FDG}$ PET/CT. J Nucl Med 45: 279-284.

56 Cho, W.I. and U.K. Chang, Comparison of MR imaging and FDG-PET/ $\mathrm{CT}$ in the differential diagnosis of benign and malignant vertebral compression fractures. J Neurosurg Spine, 2011. 14(2): p. 177-83.

57 Shin DS (2008) Differentiation between malignant and benign pathologic fractures with F-18-fluoro-2-deoxy-D-glucose positron emission tomography/computed tomography. Skeletal Radiol 37: 415-421.

58 De Smet AA, Neff JR (1985) Pubic and sacral insufficiency fractures: clinical course and radiologic findings. AJR Am J Roentgenol 145: 601-606.

59 Gotis-Graham I, McGuigan L, Diamond T, Portek I, Quinn R, et al. (1994) Sacral insufficiency fractures in the elderly. J Bone Joint Surg $\mathrm{Br} 76:$ 882-886.

60 Blomlie V, Rofstad EK, Talle K, Sundfør K, Winderen M, et al. (1996) Incidence of radiation-induced insufficiency fractures of the female pelvis: evaluation with MR imaging. AJR Am J Roentgenol 167: 1205 1210.

61 Peh WC, Khong PL, Sham JS, Ho WY, Yeung HW (1995) Sacral and pubic insufficiency fractures after irradiation of gynaecological malignancies. Clin Oncol (R Coll Radiol) 7: 117-122.

62 Schindler OS, Watura R, Cobby M (2007) Sacral insufficiency fractures. J Orthop Surg (Hong Kong) 15: 339-346.

63 Blake SP, Connors AM (2004) Sacral insufficiency fracture. Br J Radiol 77: 891-896.

64 Smith DK, Dix JE (2006) Percutaneous sacroplasty: long-axis injection technique. AJR Am J Roentgenol 186: 1252-1255.

65 Stäbler A, Beck R, Bartl R, Schmidt D, Reiser M (1995) Vacuum phenomena in insufficiency fractures of the sacrum. Skeletal Radiol 24: 31-35.

66 Cabarrus MC, Ambekar A, Lu Y, Link TM (2008) MRI and CT of insufficiency fractures of the pelvis and the proximal femur. AJR Am J Roentgenol 191: 995-1001.

67 Tsiridis E, Upadhyay N, Giannoudis PV (2006) Sacral insufficiency fractures: current concepts of management. Osteoporos Int 17: 1716-1725.

68 Brahme SK, Cervilla V, Vint V, Cooper K, Kortman K, et al. (1990) Magnetic resonance appearance of sacral insufficiency fractures. Skeletal Radiol 19: 489-493.

69 Ries T (1983) Detection of osteoporotic sacral fractures with radionuclides. Radiology 146: 783-785.

70 Finiels H, Finiels PJ, Jacquot JM, Strubel D (1997) [Fractures of the sacrum caused by bone insufficiency. Meta-analysis of 508 cases] Presse Med 26: 1568-1573.

71 Fujii M, Abe K, Hayashi K, Kosuda S, Yano F, et al. (2005) Honda sign and variants in patients suspected of having a sacral insufficiency fracture. Clin Nucl Med 30: 165-169. 